\title{
Regulating Bacterial Virulence with RNA
}

\author{
Juan J. Quereda ${ }^{1,2,3}$ and Pascale Cossart ${ }^{1,2,3^{*}}$
}

${ }^{1}$ Institut Pasteur, Unité des Interactions Bactéries-Cellules, Paris F-75015, France.

${ }^{2}$ Institut National de la Santé et de la Recherche Médicale, U604, Paris F-75015, France.

${ }^{3}$ Institut National de la Recherche Agronomique, USC2020, Paris F-75015, France.

Juan J. Quereda: juan-jose.quereda-torres@pasteur.fr

* Corresponding author: Pascale Cossart. pascale.cossart@pasteur.fr. Institut Pasteur. 25-28 rue du Dr Roux.75015, Paris, France.

Shortened running title: regulating Bacterial Virulence with RNA 


\begin{tabular}{|c|c|c|}
\hline ABSTRACT & & \\
\hline INTRODUCTION & & \\
\hline L. MONOCYTOGENES & $\begin{array}{l}\text { Several RNA regulators modulate the } \\
\text { saprophytic versus pathogenic lifestyle }\end{array}$ & - PrfA expression \\
\hline & & $\begin{array}{l}\text { - Flagellum } \\
\text { biosynthesis: the } \\
\text { excludon concept }\end{array}$ \\
\hline & $\begin{array}{l}\text { Rli55 is a riboswitch-regulated ncRNA that } \\
\text { sequesters the two-component response } \\
\text { regulator EutV }\end{array}$ & \\
\hline & $\begin{array}{l}\text { A riboswitch-regulated asRNA controls } \\
\text { propanediol utilization }\end{array}$ & \\
\hline & $\begin{array}{l}\text { Rli27 regulates a cell wall protein important } \\
\text { for bacterial survival in blood }\end{array}$ & \\
\hline S. TYPHIMURIUM & $\begin{array}{l}\text { IsrM regulates the Salmonella pathogenicity } \\
\text { island } 1\end{array}$ & \\
\hline & $\begin{array}{l}\text { The leader mRNA of the } m g t C B R \text { operon } \\
\text { senses ATP and proline intracellular levels }\end{array}$ & \\
\hline & $\begin{array}{l}\text { PinT controls the expression of bacterial } \\
\text { virulence genes and causes pervasive changes } \\
\text { in host transcripts }\end{array}$ & \\
\hline V. CHOLERAE & $\begin{array}{l}\text { Qrr 1-5 small ncRNAs regulate colonization } \\
\text { and escape from the host }\end{array}$ & \\
\hline
\end{tabular}




\begin{tabular}{|l|l|l|}
\hline & TarB controls intestinal colonization & \\
\hline S. AUREUS & VqmR represses a biofilm regulator & \\
& RNAIII controls transition from colonization & \\
\hline & The ciss-asRNA SprA1 as also controls in trans & \\
& a hemolytic peptide & \\
\hline & icaR RBS and 3'-UTR base pairing in the & \\
CONCLUSIONS AND & control of biofilm formation & \\
\hline
\end{tabular}

Keywords: RNA, virulence, pathogen, regulation 


\section{ABSTRACT}

Noncoding RNAs (ncRNAs) regulating virulence have been identified in most pathogens. The intent of this review is to discuss RNA-mediated mechanisms exploited by bacterial pathogens to successfully colonize their hosts and infect them. The most representative RNA-mediated regulatory mechanisms employed by two intracellular (Listeria monocytogenes and Salmonella enterica serovar typhimurium (S. Typhimurium)) as well as two extracellular (Vibrio cholerae and Staphylococcus aureus) bacterial pathogens are discussed. The RNA-mediated regulators (e.g. thermosensors, riboswitches, Cis and trans -encoded RNAs) used for adaptation to the specific niches colonized by these bacteria (intestine, blood or the intracellular environment for example) will be reviewed in the framework of the specific pathophysiological aspects of the diseases caused by these microorganisms. A critical discussion of the newest findings in the field of bacterial ncRNAs will be provided showing how examples in model pathogens could pave the way for the discovery of new mechanisms in other medically important bacterial pathogens.

\section{INTRODUCTION}

Bacterial pathogens have evolved mechanisms to sense the host environment and to adapt constantly to the specific niche they colonize, regulating exquisitely the production of specialized virulence factors (78). Adaptation of virulence factor production to specific stimuli can be controlled at the transcriptional, post-transcriptional, translational and post-translational levels through complex regulatory networks in bacteria.

More than 40 years ago, the central dogma of molecular biology proposed that DNA contains the information to encode all the proteins of a living organism, while three different categories of RNA translate this code into proteins (22). The three groups of RNA include: messenger RNA (mRNA) also 
known as coding-RNA, transfer RNA (tRNA) and finally ribosomal RNA (rRNA). RNA species (Ribozymes) that catalyze biochemical reactions like enzymes do, were then discovered. In addition to tRNA, rRNA and ribozymes, other ncRNAs were identified and they have been found to have complex regulatory roles in mammalian and bacterial cells $(26 ; 100)$. As a group, these RNAs are termed ncRNAs and they modulate transcription, mRNA stability, translation, and DNA maintenance or silencing through different mechanisms which in bacteria include $(34 ; 65 ; 85 ; 96 ; 103)$ : (i) changes in RNA conformation of the 5' UTR leading to transcriptional read-through/induced premature termination or activation/inhibition of translation (RNA Thermosensors, pHsensors and riboswitches) $(41 ; 56 ; 61)$; (ii) perfect base pairing between an antisense RNA (asRNA) and the gene that is encoded on the opposite strand (86); (iii) imperfect base pair interactions of a ncRNA and its target RNA encoded elsewhere on the chromosome $(6 ; 10 ; 28 ; 29 ; 42 ; 75 ; 84 ; 93)$; (iv) regulation of protein functions by sequestration of proteins from their normal targets or by modification of their enzymatic activity (95; 101); and (v) interactions with DNA (e.g. crRNAs of the immunity CRISPR system) (18; 68). Due to space limitations, the reader is referred to excellent reviews focused on regulatory RNAs and their mechanism of action as well as on the CRISPR/Cas system and the role of crRNAs in virulence (14; 18; $47 ; 68 ; 95 ; 96 ; 100 ; 107)$.

Bacterial ncRNAs size usually varies between 50 and 400 nucleotides (nt) in length (68). Most ncRNAs are transcribed from intergenic regions, while others are transcribed from an mRNA internal promoter. Finally, another class of RNA can be generated from riboswitches and from longer RNAs (16; 17; 43; 56). High-throughput technologies have recently accelerated discoveries in the bacterial RNA field (7). For example, genome wide expression studies using tiling arrays and RNA-seq technologies led to major progress in the discovery of ncRNAs in bacterial pathogens like L. monocytogenes, S. aureus, S. Typhimurium, V. Cholerae, Helicobacter pylori, Chlamydia trachomatis or Pseudomonas aeruginosa 
among others $(1 ; 46 ; 60 ; 89 ; 98 ; 105 ; 108)$. The current omics era made possible the use of a 'dual RNAseq' approach which profiles RNA expression simultaneously in a pathogen and its host during infection being able to reveal the molecular impact of bacterial ncRNAs. This technique is a paradigm to increase the knowledge of the interaction between bacterial pathogens and their hosts, as well as a new tool to discover hidden functions of pathogen genes $(105 ; 106)$. Finally, a new method termed term-seq was set up to quantitatively map all exposed RNA 3' ends in individual bacteria as well as in microbiomes. This technique can assess activities of ribo-regulators and allows unbiased genome-wide identification of genes regulated by premature transcription termination (23).

Bacterial ncRNAs modulate the response to environmental changes, control physiology, development and metabolism and regulate virulence in pathogenic bacteria $(14 ; 34 ; 68 ; 95 ; 100)$. Here we will present some striking examples of ncRNAs in intracellular and extracellular pathogens.

\section{MONOCYTOGENES}

L. monocytogenes is a gram-positive bacterium that lives in the soil as a saprophyte but is also a pathogen responsible for listeriosis, a food borne disease characterized by bacteremia, meningoencephalitis, abortion or neonatal sepsis and a case-fatality rate of $30 \%(20)$. L. monocytogenes is able to colonize the intestine, promote its own internalization in mammalian cells, disrupt the internalization vacuole and escape into the cytoplasm, where an actin-based motility system dependent on activation of the Arp2/3 complex by the bacterial surface protein ActA propels the bacterium and allows spreading to neighboring cells $(20 ; 72 ; 76)$.

Several RNA regulators modulate the saprophytic versus pathogenic lifestyle.

\section{- PrfA expression}


PrfA is a transcriptional regulator belonging to the cAMP receptor protein (Crp)/fumarate nitrate reductase regulator (Fnr) family which regulates most virulence factors of $L$. monocytogenes (internalins InlA and InlB, the pore-forming toxin listeriolysin $\mathrm{O}$, the phospholipases PlcA and PlcB, the Mpl protease, the actin polymerizing protein ActA, the secreted protein InlC, and the sugar phosphate permease Hpt). PrfA translation is controlled by a 5'UTR thermosensor that adopts alternative secondary structures depending on the temperature. At temperatures $\leq 30^{\circ} \mathrm{C}$ this thermoswitch sequesters the prfA RBS due to formation of an RNA hairpin, but at $37^{\circ} \mathrm{C}$ (temperature of mammalian hosts) the thermosensor is destabilized allowing PrfA translation and virulence factor production (Figure 1A) (41).

In addition to its 5'UTR thermosensor, PrfA is regulated in trans by two small ncRNA generated from the S-adenosylmethionine (SAM) riboswitches, SreA and SreB (56). SAM binding to these SAM riboswitches causes formation of a structure that terminates transcription, generates a small ncRNA and prevents synthesis of the downstream mRNA. The small ncRNAs SreA and SreB can base-pair with the RBS region of the prfA mRNA and block translation initiation. The impact of the SAM riboswitches on PrfA expression highlights the presence of a subtle network linking nutrient availability and virulence in L. monocytogenes (56).

\section{- Flagellum biosynthesis: the excludon concept}

Synthesis of the flagellum in L. monocytogenes is controlled by an excludon. The name excludon was coined to name a locus where an asRNA simultaneously represses expression of the overlapping transcripts and encodes an mRNA for one or several neighboring genes $(86 ; 98)$. At $30^{\circ} \mathrm{C}, \mathrm{L}$. monocytogenes expresses flagella and exhibits swimming motility in liquid environment or swarming motility on semi-solid surfaces to access nutrient sources. At host temperature $\left(37^{\circ} \mathrm{C}\right)$, the repressor 
MogR blocks transcription of flagella genes and switches off flagella formation (47). Among the genes repressed by MogR, the fli operon (lmo0675-lmo0689) is transcribed opposite of the $m o g R$ operon and encodes proteins required for the synthesis of the flagellum. Two promoters have been identified for $\operatorname{mog} R$ : a sigma B dependent promoter $\mathrm{P} 1$ at $1,697 \mathrm{nt}$ from the $\operatorname{mog} R$ ATG and a second promoter $\mathrm{P} 2$ at $45 \mathrm{nt}$ from the ATG (98). The mRNA from P2 is constitutively expressed. Interestingly, expression from P1 generates a long asRNA (anti0677) which overlaps the first three genes of the fli operon (lmo0675lmo0676-lmo0677) that have divergent orientation (Figure 1B). Imo0676 and lmo0677 encode FliP and FliQ, respectively, and together with FliR (lmo0678) form the flagellum export apparatus. The long asRNA anti0677 negatively regulates the expression of the sense transcript, inhibiting the synthesis of the Lmo0675, FliP and FliQ flagellum export apparatus while concomitantly allows the expression of MogR. During infection at $37^{\circ} \mathrm{C}$, two independent mechanisms switch off the flagellum production: 1) an inhibition mediated by the antisense component of anti0677 and 2) a transcriptional repression mediated by the production of MogR (Figure 1B) (86; 98). Importantly, the mogR-lmo0675-lmo0676Imo0677 was the first reported excludon.

\section{Rli55 is a riboswitch-regulated ncRNA that sequesters the two-component response regulator}

\section{EutV.}

The ethanolamine utilization operon (eut) is important for L. monocytogenes pathogenesis in an intravenous mouse infection model (62). eut genes are also important for S. Typhimurium after oral infection (97). The enzymes of the ethanolamine utilization pathway use vitamin B12 as a cofactor and pathogens have evolved sophisticated tools to optimize eut expression when both vitamin B12 and ethanolamine are present (62). The eut operon is transcribed in the presence of ethanolamine and vitamin B12 under the control of the EutVW two-component system, where EutW is a sensor kinase, 
and EutV is an antiterminator which regulates the eut messenger RNAs through binding dual-hairpin structures that overlap terminators. EutV thus prevents transcription termination (Figure 1C). eut expression also depends on a riboswitch that binds vitamin B12 and controls the expression of the ncRNA, Rli55. In the absence of vitamin B12, a full length Rli55 containing an EutV-binding site is transcribed, which sequesters the two-component response regulator EutV and impedes eut transcription. When vitamin $\mathrm{B} 12$ is present, the Rli55-riboswitch terminates Rli55 transcription upstream of the EutV-binding site. As a consequence, EutV is free to bind the nascent eut transcripts and avoid its premature termination (Figure 1C) (62). Interestingly, a similar mechanism has been described in Enterococcus faecalis, where a riboswitch-containing the small ncRNA EutX controls eut gene expression by sequestration of the EutV response regulator (25).

\section{A riboswitch-regulated asRNA controls propanediol utilization}

Propanediol is an important nutrient source for bacterial pathogens during infection $(12 ; 63) . L$. monocytogenes up-regulates the propanediol utilization operon $(p d u)$ during the intestinal stage of infection of mice (3). AspocR is a vitamin B12 riboswitch regulated asRNA which is in a convergent orientation to $p o c R$, a gene encoding a transcription factor that is expressed in the presence of 1,2propanediol, and triggers the expression of the $p d u$ genes. In absence of vitamin $\mathrm{B} 12$, the long form of AspocR is expressed which inhibits pocR expression and consequently the activation of the $p d u$ genes.

Binding of vitamin B12 to the riboswitch terminates the transcription of AspocR prematurely and transcription of $p o c R$ can proceed (Figure 1D). This elegant system allows that the $p d u$ genes are maximally expressed only when 1,2-propanediol and vitamin B12 are present (63). 


\section{Rli27 regulates a cell wall protein important for bacterial survival in blood}

After crossing the intestinal barrier, L. monocytogenes disseminates through the blood to the spleen, liver, brain and placenta. Lmo0514 is a L. monocytogenes LPXTG surface protein highly upregulated during the blood stage or growth within eukaryotic cells. Lmo0514 is required for survival in plasma and for virulence in mice $(74 ; 75)$. Lmo0514 is transcribed from two different promoters, producing transcripts with 5'UTR of 28 and 234 nt. The 5'UTRs of 1 mo0514 transcripts occlude the RBS preventing translation. The transcript containing the long 5'UTR is upregulated in intracellular bacteria and is the target of the trans-acting small ncRNA Rli27, which is also upregulated in the intracellular environment and in blood $(75 ; 77 ; 98)$. Rli27 interaction with the 5 'UTR of $1 m 00514$ unmasks the RBS and promotes translation (Figure 1E). This case is another example of a bacterial process related to virulence controlled by different layers of regulation: Firstly, a transcriptional regulation by two different $l m o 0514$ promoters, and secondly a translational regulation via Rli27.

\section{S. TYPHIMURIUM}

S. Typhimurium is a gram-negative bacterium that can infect a broad range of hosts (e.g. humans, cattle, swine and poultry). Salmonellae are typically acquired by the oral ingestion of contaminated food or water and cause diverse diseases ranging from self-limiting gastroenteritis to life-threating bacteremia and systemic infection mainly in immunosuppressed hosts, in very young and older individuals (45). S. Typhimurium can invade and survive inside several mammalian cell types. Adaptation to an intracellular lifestyle is controlled by regulatory systems, including two-component systems like PhoP-PhoQ. After internalization S. Typhimurium resides in a specialized phagosomal compartment named the Salmonella containing vacuole (SCV), which is mildly acidic and contains low levels of available proline $(45 ; 48$; 57). 


\section{IsrM regulates the Salmonella pathogenicity island 1}

The Salmonella pathogenicity island 1 (SPI-1) encodes a type III secretion system that forms a syringelike organelle able to inject effector proteins into the cytosol of eukaryotic cells to manipulate the host cellular functions. SPI-1 is necessary for the initial interaction of Salmonella with intestinal epithelial cells (30). IsrM is a small ncRNA encoded in a different pathogenicity island of Salmonella. IsrM inhibits in trans HilE expression by binding to its mRNA around the RBS sequence, resulting in its translational repression (Figure 2A). HilE is a global negative regulator of the expression of numerous SPI-1 genes by sequestering HilD, a major SPI-1 transcriptional activator (33). IsrM is highly expressed during infection, particularly in the ileum. IsrM is dispensable for Salmonella growth in vitro but important for invasion of epithelial cells, intracellular replication inside macrophages, and virulence in mice. This example shows how a ncRNA can be a core regulator of virulence factors controlling the intestinal colonization stage of a foodborne bacterial pathogen.

\section{The leader mRNA of the mgtCBR operon senses ATP and proline intracellular levels}

$\mathrm{MgtC}$ is a virulence factor of S. Typhimurium regulated by PhoP-PhoQ and required for intracellular proliferation inside macrophages and for virulence in mice (52). MgtC is an inner membrane protein that promotes pathogenicity by maintaining ATP homeostasis through the inhibition of the bacterium's own F1F0 ATP synthase (51). MgtC is regulated at various levels: transcription initiation, elongation, mRNA stability, translation, and protein degradation (52). $m g t C$ is expressed together with two other genes, $m g t B$ and $m g t R$, comprising the $m g t C B R$ operon. Transcription of the operon generates a 5' UTR of 296 bp. This long leader RNA encodes two short open reading frames (ORFs): $m g t M$ and $m g t P$. These short ORFs can respectively sense ATP and tRNA ${ }^{\text {Pro }}$ levels and consequently adopt two sets of alternative stem-loop structures. The stem-loop structures formed affect the coupling/uncoupling of transcription of the $m g t C B R 5^{\prime} \mathrm{UTR}$ with translation of $m g t M$ or $m g t P$, dictating whether transcription can continue or 
not into the $m g t C B R$ operon. The SCV is mildly acidic, a condition that can generate high ATP levels inside S. Typhimurium during infection. Elevated intracellular ATP levels promote the formation of a stem-loop at MgtM that allows transcription to continue into the downstream $m g t C$ gene promoting virulence (Figure 2B) (49). Similarly, the reduced levels of intracellular charged tRNA ${ }^{\text {Pro }}$ uncouple transcription and translation at $m g t P$ and favor formation of a stem-loop which enhances transcription of the $m g t C$ operon. Moreover, this stem-loop releases the RBS and the start codon of the $m g t C$ gene (previously occluded), further facilitating $m g t C$ translation (50). Interestingly, the low proline / hyperosmotic stress typically found in the SCV decreases proline levels available to charge tRNA ${ }^{\text {Pro, }}$ finally leading to enhanced $m g t C$ operon transcription (48). The $m g t C$ operon is thus controlled by a leader mRNA with two attenuators in tandem that respond to ATP and tRNA ${ }^{\text {Pro }}$ levels of the SCV.

\section{PinT controls the expression of bacterial virulence genes and causes pervasive changes in host transcripts}

Dual RNA-seq of Salmonella infected human cells revealed that PinT is a PhoP-dependent ncRNA that is highly activated after infection (105). PinT simultaneously acts on SPI-1 effectors and SPI-2 virulence genes, shaping the transition from invasion to intracellular replication. Firstly, PinT base pairs with the SPI-1 effectors SopE and SopE2 near the start codon which may cause translational repression. Secondly, PinT directly represses the mRNA encoding the protein CRP which through an unknown mechanism regulates SPI-2 activation (105). This riboregulatory activity of PinT has widespread consequences in coding and noncoding transcripts of infected human cells. For example, PinT reduces the activation of the Suppressor of cytokine signaling 3 (SOCS3, a key regulator of JAK-STAT signaling) whose function is to inhibit the phosphorylation of the STAT3 transcription factor. Moreover, PinT activity decreases the mRNA levels of the pro-inflammatory Interleukin 8 in infected cells (105). 
This example shows how a small ncRNA can modulate temporally virulence gene expression and manipulate key host cell pathways and promote bacterial replication.

\section{CHOLERAE}

$V$. cholerae is a gram negative, motile bacterium that lives in aquatic environments. $V$. cholerae is transmitted to humans by consumption of contaminated water or food and causes the epidemic diarrheal disease cholera, which is endemic in more than 50 countries and also causes large epidemics $(2 ; 36)$. A master virulence regulator of $V$. cholerae, ToxT, is regulated post-transcriptionally by an RNA thermosensor which allows translation at $37^{\circ} \mathrm{C}$ (104). Different $V$. cholerae ncRNAs control the expression of ToxT, which directly activates production of virulence genes crucial for infection, including the cholera toxin (CTX) and the toxin-coregulated pilus (TCP) which allows colonization of the host (58).

\section{Qrr 1-5 small ncRNAs regulate colonization and escape from the host}

Quorum sensing (QS) is a microbial cell-to-cell communication-based process leading to the coordination of various common bacterial behaviors including virulence factors expression. In the case of $V$. Cholerae, the phosphorylation of LuxO at low cell density (LCD) promotes transcription of five small ncRNAs named Qrr 1-5. These ncRNAs activate the translation of aphA, the LCD master regulator and repress the translation of hapR, the high cell density (HCD) master regulator (Figure 3A). At HCD, the phosphorylation of LuxO is inhibited and HapR is expressed $(80 ; 87)$. Thus, at LCD typically found at early stages of infection, AphA activates the ToxT virulence regulon with expression of the TCP and the CTX (91). At HCD found at late stages of infection, HapR represses aphA transcription and consequently, the production of TCP and CTX virulence factors, but activates 
expression of proteases such as the hapA hemaglutinin/protease gene that permit $V$. cholerae exit from the host (Figure 3B) $(35 ; 96 ; 111)$. Moreover, Qrr ncRNAs control the Type 6 Secretion Systems (T6SS) at early stages of infection via two mechanisms: 1) they repress translation of hapR which decrease expression of the two small T6SS of $V$. cholerae; and 2) they repress T6SS through base pairing to the mRNA encoding the large T6SS of this bacterium. T6SS are important during the infectious cycle of $V$. cholerae since they contribute to phagocytic cells killing and attack of other prokaryotes $(87 ; 88)$, as well as to escape from the host during late stages of infection (110). These examples show how Qrr small ncRNAs constitute a dynamic system that allows cell-cell communication in $V$. cholerae to synchronize collective behavior.

\section{TarB controls intestinal colonization}

TarB is a ncRNA directly controlled by ToxT and upregulated during infection. TarB is encoded on the TCP island together with many virulence-associated genes (24). TarB stabilized by Hfq downregulates the expression of VspR, a transcription factor present in the Vibrio $7^{\text {th }}$ pandemic island-1 which represses the expression of several genes in this island, including a dinucleotide cyclase (DNCV). Importantly, c-AMP-GMP produced by DNCV is required for $V$. cholerae downregulation of chemotaxis and for intestinal colonization, a phenotype related to hyperinfectivity (24). TarB together with Qrr 1-5 tightly control the crucial process of $V$. cholerae intestinal colonization.

\section{VqmR represses a biofilm regulator}

A biofilm is a three-dimensionally structured, bacterial community embedded in an extracellular polymeric substance. In $V$. cholerae, VpsT is a major transcriptional regulator of genes involved in biofilm formation that triggers the expression of genes required for synthesis of polysaccharide at LCD 
(102). Transcription of $v p s T$ is itself activated by the biofilm regulator VpsR (94). A Hfq-dependent ncRNA, VqmR, hybridizes with $v p s T$ and presumably inhibits ribosome binding resulting in lower protein levels of VpsT. Thus, VpsT expression is regulated transcriptionally by VpsR (38) and translationally by VqmR $(70 ; 94 ; 102)$. Interestingly, these examples show how in contrast to other pathogenic bacteria, V. Cholerae quorum sensing represses virulence gene expression and biofilm formation (90).

\section{S. AUREUS}

S. aureus is an opportunistic gram positive bacterium ubiquitous in the environment and frequently found in the nose, respiratory tract, and on the skin. It is responsible for nosocomial and communityacquired infections with high mortality. S. aureus has been classically classified as an extracellular pathogen, however increasing evidence shows that it has the potential to enter and survive within host cells (31).

\section{RNAIII controls transition from colonization to dissemination mode}

The AgrC/AgrA two component system senses $S$. aureus density and controls expression of virulence and other accessory genes. This system encodes an autoactivating peptide (AIP) that is sensed by the histidine kinase receptor AgrC which phosphorylates the response regulator AgrA. Distinct from other systems, the effector is a $514 \mathrm{nt}$ RNA named RNAIII $(66 ; 67)$. RNAIII is a multifunctional RNA that encodes the cytolytic peptide $\delta$-haemolysin and also acts as a RNA regulating the translation and/or the stability of other mRNAs (39). Importantly, most S. aureus clinical isolates contain the Agr system (99). Following a quorum-sensing signal, RNAIII regulates the switch from expression of several surface proteins important for adhesion to secretion of toxins. By doing so, RNAIII controls the transition of the 
S. aureus population from a defensive mode (colonization) to an offensive mode (spreading) (Figure 4A and 4B) (11). RNAIII binds to Protein A, Coagulase, Sbi and the fibrinogen-binding protein SA1000 (all of them adhesin factors) mRNAs preventing initiation of translation and recruiting the RNase III which rapidly degrades these repressed mRNAs $(9 ; 15 ; 19 ; 38)$. RNAIII also inhibits translation of rot (the repressor of toxins), which finally results in transcription of toxins including $\alpha$-haemolysin, staphylococcal protease and lipase that contribute to tissue invasion (32; 96). Additionally, RNAIII activates translation of the $\alpha$-haemolysin by interacting with the 5' UTR of hla mRNA and liberating the RBS after the resolution of an inhibitory secondary structure (64). Due to the dependence on RNAIII for the synthesis of exotoxins, it has been suggested that the Agr system is critical for full expression of virulence, particularly during acute infection (11).

\section{The cis-asRNA SprA1 as also controls in trans a hemolytic peptide}

SprA1 is a 30-residue toxic peptide that lyses erythrocytes and has antimicrobial activity against other bacteria (including $S$. aureus itself) (82), a common characteristic shared by other families of peptides $(53 ; 71 ; 73)$. SprA1 is encoded in a type I toxin-antitoxin (TA) module within a pathogenicity island. The genes encoding the SprA1 toxic peptide and its asRNA SprA1 as are located on opposite strands and possess a $3^{\prime}$ overlap. Surprisingly, $\mathrm{SprA}_{\text {as }}$ also acts in trans by means of a domain outside its target complementary sequence. $\mathrm{SprA}_{1}$ as base pair with $\operatorname{sprAl} \mathrm{mRNA}$, occluding translation initiation signals and preventing its translation. To avoid peptide toxicity during $S$. aureus growth $\operatorname{sprAl}$ and $\mathrm{SprA}_{1}$ as are concomitantly expressed. Acidic and oxidative stresses trigger SprA1 expression by reducing $\mathrm{SprA}_{1}$ as levels, which leads to suggest that as an altruistic behavior, some $S$. aureus may express SprA1 to facilitate departure from the phagosomes of host immune cells for spreading (83). This example clearly 
shows that the demarcation between cis- and trans-RNAs is sometimes ill defined and suggests that there is a need for mechanistic re-evaluation of asRNAs (82).

\section{icaR RBS and 3'-UTR base pairing in the control of biofilm formation}

Biofilm formation is the main cause of implant infections in orthopedics patients (5). The S. aureus biofilm synthesis depends on the enzymes encoded by the icaADBC operon (21). IcaR is a transcriptional repressor encoded at the ica locus that binds to the icaADBC promoter and inhibits icaADBC expression (40). A UCCCCUG motif located at the 3'-UTR of the icaR mRNA binds the RBS region at the 5'-UTR, inhibiting ribosome loading and generating a double-stranded substrate for RNase III which promotes mRNA decay. Importantly, substitution or deletion of the UCCCCUG motif reduced the 3'-UTR/RBS interaction facilitating icaR mRNA translation and consequently inhibiting biofilm formation (79). Whether the 5' UTR and the 3' UTR interaction is inter or intramolecular remains to be elucidated. The present example shows how bacterial 3'UTRs provide regulatory elements to modulate gene expression, a field that has been poorly investigated when compared to their eukaryotes counterparts (79).

\section{CONCLUSIONS AND PERSPECTIVES}

Despite the continuously growing diversity of reported mechanisms of action for ncRNA regulating virulence, one still expects that new mechanisms playing a crucial role in the infection process will be discovered. Several aspects of known RNA-mediated regulation are still elusive and should also be soon clarified. First it will be important to investigate ncRNA expression at the single cell level, since the "averaged" data obtained when a population of bacteria is used could hide important regulatory responses and mechanisms employed by specific subpopulations of bacterial pathogens $(69 ; 81)$. Little is 
known about how one specific ncRNA regulates simultaneously different target molecules. New technologies such as single-molecule fluorescence in situ hybridization with super-resolution microscopy may enable the in vivo determination of ncRNA target search kinetics (27). This technique could be instrumental in our current understanding of how bacteria prioritize target mRNAs during infection (27).

New approaches should also provide a deeper understanding of the global regulation of the ncRNAomes. For example, the high throughput biochemical profiling approach termed gradient profiling sequencing, as done recently, can help analyzing global RNA landscapes by partitioning transcripts into diverse coding and noncoding clusters based on their shared RNA-protein interactions (92). In Salmonella this method has allowed identification of a large class of structured small RNAs that form stable complexes with the conserved RNA-binding protein ProQ (92). This technique will help to describe functional RNA landscapes in interesting organisms that are emerging from microbiome and environmental studies.

Moreover, there is growing interest in the RNA field since it has been shown that bacterial pathogens ncRNAs may act as signaling molecules able to modulate host gene expression programs $(8 ; 54)$. This is particularly well illustrated in Caenorhabditis elegans where the E. coli endogenous ncRNAs OxyS and DsrA modify the expression of host genes impairing the chemosensory behavior and decreasing its longevity, respectively (54). More recently, another study showed that uropathogenic E. coli releases membrane vesicles (MV) containing mRNAs, rRNA, tRNAs and small ncRNAs. These MV can be delivered into cultured bladder epithelial cells and their RNA transported into the host cell cytoplasm and nucleus (8). Interestingly, the intestinal microbiota interferes with the microRNA (miRNA) response of the host intestinal tissue upon oral bacterial infection (4). This example shows the existence of a miRNA modulation through which the gut microbiota influences host transcriptional programs during 
infection. Conversely, miRNA from the host affect bacterial programs (55). In particular, it has been shown that intestinal epithelial cells, Paneth cells and goblet cells release extracellular vesicles containing miRNAs than can enter E. coli and F. nucleatum regulating bacterial gene transcripts and growth in vitro (55). Therefore, there is a ncRNA cross-talk between bacterial pathogens and the host (26) suggesting that ncRNAs are potential targets to manipulate the gut microbiome or even bacterial infections in other organs.

In addition, a link between antibiotics exposure or resistance and ncRNA expression has been repeatedly reported: studies in S. Typhimurium and $S$. aureus have first shown that some small ncRNAs are overexpressed as a result of antibiotic exposure $(37 ; 109)$. More recently, it was shown that many antibiotics resistance genes, in both pathogenic bacteria (e.g. L. monocytogenes) and in the human microbiome, are regulated via termination-based ribo-regulators that permit read-through when the antibiotic is present (23). Notably, some E. coli and S. Typhimurium small ncRNAs were shown to be important for bacterial viability in response to antibiotics $(44 ; 109)$.

In conclusion, RNAs are very versatile molecules able to modulate bacterial metabolic routes, antimicrobial resistance and virulence. There is a growing interest to use their properties to generate RNA-based therapeutics in the treatment of genetic disorders, cancers, viruses and bacteria $(13 ; 44 ; 59$; 109). As our comprehension of ncRNAs increases, there is little doubt that their therapeutic applications will expand. 


\section{ACKNOWLEDGEMENTS}

We thank Melodie Duval for helpful discussions and critical reading of the manuscript. We thank Servier Medical Art (http://www.servier.com/Powerpoint-image-bank) for providing some of the drawings used. This work was supported by the Institut Pasteur, Institut National de la Santé et de la Recherche Médicale (Unité 604), Institut National de la Recherche Agronomique (Unité Sous Contrat 2020), National Research Agency (ANR; ERANET Infect-ERA PROANTILIS ANR-13-IFEC-0004-

02), the French Government's Investissement d'Avenir program, Laboratoire d'Excellence “Integrative Biology of Emerging Infectious Diseases" (ANR-10-LABX-62-IBEID), the European Research Council (ERC) (Advanced Grant \#233348 MODELIST, H2020-ERC-2014-ADG 670823-BacCellEpi), Human Frontiers Science Program Organization (RGP0011/2013), Fondation Balzan and Fondation Le Roch Les Mousquetaires. PC is an International Senior Research Scholar of the Howard Hughes Medical Institute.

\section{REFERENCES}

1. Albrecht M, Sharma CM, Reinhardt R, Vogel J, Rudel T. 2010. Deep sequencing-based discovery of the Chlamydia trachomatis transcriptome. Nucleic Acids Res 38:868-77

2. Almagro-Moreno S, Pruss K, Taylor RK. 2015. Intestinal Colonization Dynamics of Vibrio cholerae. PLoS Pathog 11:e1004787

3. Archambaud C, Nahori MA, Soubigou G, Becavin C, Laval L, et al. 2012. Impact of lactobacilli on orally acquired listeriosis. Proc Natl Acad Sci U S A 109:16684-9

4. Archambaud C, Sismeiro O, Toedling J, Soubigou G, Becavin C, et al. 2013. The intestinal microbiota interferes with the microRNA response upon oral Listeria infection. MBio 4:e00707-13

5. Arciola CR, Campoccia D, Speziale P, Montanaro L, Costerton JW. 2012. Biofilm formation in Staphylococcus implant infections. A review of molecular mechanisms and implications for biofilmresistant materials. Biomaterials 33:5967-82

6. Bandyra KJ, Said N, Pfeiffer V, Gorna MW, Vogel J, Luisi BF. 2012. The seed region of a small RNA drives the controlled destruction of the target mRNA by the endoribonuclease RNase E. Mol Cell 47:943-53

7. Barquist L, Vogel J. 2015. Accelerating Discovery and Functional Analysis of Small RNAs with New Technologies. Annu Rev Genet 49:367-94 
8. Blenkiron C, Simonov D, Muthukaruppan A, Tsai P, Dauros P, et al. 2016. Uropathogenic Escherichia coli Releases Extracellular Vesicles That Are Associated with RNA. PLoS One 11:e0160440

9. Boisset S, Geissmann T, Huntzinger E, Fechter P, Bendridi N, et al. 2007. Staphylococcus aureus RNAIII coordinately represses the synthesis of virulence factors and the transcription regulator Rot by an antisense mechanism. Genes Dev 21:1353-66

10. Bossi L, Schwartz A, Guillemardet B, Boudvillain M, Figueroa-Bossi N. 2012. A role for Rho-dependent polarity in gene regulation by a noncoding small RNA. Genes Dev 26:1864-73

11. Bronesky D, Wu Z, Marzi S, Walter P, Geissmann T, et al. 2016. Staphylococcus aureus RNAlll and Its Regulon Link Quorum Sensing, Stress Responses, Metabolic Adaptation, and Regulation of Virulence Gene Expression. Annu Rev Microbiol

12. Buchrieser C, Rusniok C, Kunst F, Cossart P, Glaser P, Listeria C. 2003. Comparison of the genome sequences of Listeria monocytogenes and Listeria innocua: clues for evolution and pathogenicity. FEMS Immunol Med Microbiol 35:207-13

13. Burnett JC, Rossi JJ. 2012. RNA-based therapeutics: current progress and future prospects. Chem Biol 19:60-71

14. Caldelari I, Chao Y, Romby P, Vogel J. 2013. RNA-mediated regulation in pathogenic bacteria. Cold Spring Harb Perspect Med 3:a010298

15. Chabelskaya S, Bordeau V, Felden B. 2014. Dual RNA regulatory control of a Staphylococcus aureus virulence factor. Nucleic Acids Res 42:4847-58

16. Chao Y, Papenfort K, Reinhardt R, Sharma CM, Vogel J. 2012. An atlas of Hfq-bound transcripts reveals 3' UTRs as a genomic reservoir of regulatory small RNAs. EMBO J 31:4005-19

17. Chao Y, Vogel J. 2016. A 3' UTR-Derived Small RNA Provides the Regulatory Noncoding Arm of the Inner Membrane Stress Response. Mol Cell 61:352-63

18. Charpentier E, Richter H, van der Oost J, White MF. 2015. Biogenesis pathways of RNA guides in archaeal and bacterial CRISPR-Cas adaptive immunity. FEMS Microbiol Rev 39:428-41

19. Chevalier C, Boisset S, Romilly C, Masquida B, Fechter P, et al. 2010. Staphylococcus aureus RNAIII binds to two distant regions of coa mRNA to arrest translation and promote mRNA degradation. PLoS Pathog 6:e1000809

20. Cossart P. 2011. Illuminating the landscape of host-pathogen interactions with the bacterium Listeria monocytogenes. Proc Natl Acad Sci U S A 108:19484-91

21. Cramton SE, Gerke C, Schnell NF, Nichols WW, Gotz F. 1999. The intercellular adhesion (ica) locus is present in Staphylococcus aureus and is required for biofilm formation. Infect Immun 67:5427-33

22. Crick F. 1970. Central dogma of molecular biology. Nature 227:561-3

23. Dar D, Shamir M, Mellin JR, Koutero M, Stern-Ginossar N, et al. 2016. Term-seq reveals abundant riboregulation of antibiotics resistance in bacteria. Science 352:aad9822

24. Davies BW, Bogard RW, Young TS, Mekalanos JJ. 2012. Coordinated regulation of accessory genetic elements produces cyclic di-nucleotides for V. cholerae virulence. Cell 149:358-70

25. DebRoy S, Gebbie M, Ramesh A, Goodson JR, Cruz MR, et al. 2014. Riboswitches. A riboswitchcontaining SRNA controls gene expression by sequestration of a response regulator. Science 345:937-40

26. Duval M, Cossart P, Lebreton A. 2016. Mammalian microRNAs and long noncoding RNAs in the hostbacterial pathogen crosstalk. Semin Cell Dev Biol

27. Fei J, Singh D, Zhang Q, Park S, Balasubramanian D, et al. 2015. RNA biochemistry. Determination of in vivo target search kinetics of regulatory noncoding RNA. Science 347:1371-4

28. Frohlich KS, Papenfort K, Fekete A, Vogel J. 2013. A small RNA activates CFA synthase by isoform-specific mRNA stabilization. EMBO J 32:2963-79

29. Frohlich KS, Vogel J. 2009. Activation of gene expression by small RNA. Curr Opin Microbiol 12:674-82

30. Galan JE. 2001. Salmonella interactions with host cells: type III secretion at work. Annu Rev Cell Dev Biol 17:53-86 
31. Garzoni C, Kelley WL. 2009. Staphylococcus aureus: new evidence for intracellular persistence. Trends Microbiol 17:59-65

32. Geisinger E, Adhikari RP, Jin R, Ross HF, Novick RP. 2006. Inhibition of rot translation by RNAlll, a key feature of agr function. Mol Microbiol 61:1038-48

33. Gong H, Vu GP, Bai Y, Chan E, Wu R, et al. 2011. A Salmonella small non-coding RNA facilitates bacterial invasion and intracellular replication by modulating the expression of virulence factors. PLoS Pathog 7:e1002120

34. Gottesman S, Storz G. 2011. Bacterial small RNA regulators: versatile roles and rapidly evolving variations. Cold Spring Harb Perspect Biol 3

35. Hammer BK, Bassler BL. 2003. Quorum sensing controls biofilm formation in Vibrio cholerae. Mol Microbiol 50:101-4

36. Harris JB, LaRocque RC, Qadri F, Ryan ET, Calderwood SB. 2012. Cholera. Lancet 379:2466-76

37. Howden BP, Beaume M, Harrison PF, Hernandez D, Schrenzel J, et al. 2013. Analysis of the small RNA transcriptional response in multidrug-resistant Staphylococcus aureus after antimicrobial exposure. Antimicrob Agents Chemother 57:3864-74

38. Huntzinger E, Boisset S, Saveanu C, Benito Y, Geissmann T, et al. 2005. Staphylococcus aureus RNAIII and the endoribonuclease III coordinately regulate spa gene expression. EMBO J 24:824-35

39. Janzon L, Arvidson S. 1990. The role of the delta-lysin gene (hld) in the regulation of virulence genes by the accessory gene regulator (agr) in Staphylococcus aureus. EMBO J 9:1391-9

40. Jefferson KK, Cramton SE, Gotz F, Pier GB. 2003. Identification of a 5-nucleotide sequence that controls expression of the ica locus in Staphylococcus aureus and characterization of the DNA-binding properties of IcaR. Mol Microbiol 48:889-99

41. Johansson J, Mandin P, Renzoni A, Chiaruttini C, Springer M, Cossart P. 2002. An RNA thermosensor controls expression of virulence genes in Listeria monocytogenes. Cell 110:551-61

42. Kawamoto H, Koide $\mathrm{Y}$, Morita T, Aiba H. 2006. Base-pairing requirement for RNA silencing by a bacterial small RNA and acceleration of duplex formation by Hfq. Mol Microbiol 61:1013-22

43. Kawano M, Reynolds AA, Miranda-Rios J, Storz G. 2005. Detection of 5'- and 3'-UTR-derived small RNAs and cis-encoded antisense RNAs in Escherichia coli. Nucleic Acids Res 33:1040-50

44. Kim T, Bak G, Lee J, Kim KS. 2015. Systematic analysis of the role of bacterial Hfq-interacting sRNAs in the response to antibiotics. J Antimicrob Chemother 70:1659-68

45. LaRock DL, Chaudhary A, Miller SI. 2015. Salmonellae interactions with host processes. Nat Rev Microbiol 13:191-205

46. Lasa I, Toledo-Arana A, Dobin A, Villanueva M, de los Mozos IR, et al. 2011. Genome-wide antisense transcription drives mRNA processing in bacteria. Proc Natl Acad Sci U S A 108:20172-7

47. Lebreton A, Cossart P. 2016. RNA- and protein-mediated control of Listeria monocytogenes virulence gene expression. RNA Biol:0

48. Lee EJ, Choi J, Groisman EA. 2014. Control of a Salmonella virulence operon by proline-charged tRNA(Pro). Proc Natl Acad Sci U S A 111:3140-5

49. Lee EJ, Groisman EA. 2012. Control of a Salmonella virulence locus by an ATP-sensing leader messenger RNA. Nature 486:271-5

50. Lee EJ, Groisman EA. 2012. Tandem attenuators control expression of the Salmonella mgtCBR virulence operon. Mol Microbiol 86:212-24

51. Lee EJ, Pontes MH, Groisman EA. 2013. A bacterial virulence protein promotes pathogenicity by inhibiting the bacterium's own F1Fo ATP synthase. Cell 154:146-56

52. Lee JW, Lee EJ. 2015. Regulation and function of the Salmonella MgtC virulence protein. J Microbiol 53:667-72

53. Lee SW, Mitchell DA, Markley AL, Hensler ME, Gonzalez D, et al. 2008. Discovery of a widely distributed toxin biosynthetic gene cluster. Proc Natl Acad Sci U S A 105:5879-84 
54. Liu H, Wang X, Wang HD, Wu J, Ren J, et al. 2012. Escherichia coli noncoding RNAs can affect gene expression and physiology of Caenorhabditis elegans. Nat Commun 3:1073

55. Liu S, da Cunha AP, Rezende RM, Cialic R, Wei Z, et al. 2016. The Host Shapes the Gut Microbiota via Fecal MicroRNA. Cell Host Microbe 19:32-43

56. Loh E, Dussurget O, Gripenland J, Vaitkevicius K, Tiensuu T, et al. 2009. A trans-acting riboswitch controls expression of the virulence regulator PrfA in Listeria monocytogenes. Cell 139:770-9

57. Lopez-Montero N, Ramos-Marques E, Risco C, Garcia-Del Portillo F. 2016. Intracellular Salmonella induces aggrephagy of host endomembranes in persistent infections. Autophagy:1-16

58. Lowden MJ, Skorupski K, Pellegrini M, Chiorazzo MG, Taylor RK, Kull FJ. 2010. Structure of Vibrio cholerae ToxT reveals a mechanism for fatty acid regulation of virulence genes. Proc Natl Acad Sci U S A 107:2860-5

59. Lundin KE, Gissberg O, Smith Cl. 2015. Oligonucleotide Therapies: The Past and the Present. Hum Gene Ther 26:475-85

60. Mandlik A, Livny J, Robins WP, Ritchie JM, Mekalanos JJ, Waldor MK. 2011. RNA-Seq-based monitoring of infection-linked changes in Vibrio cholerae gene expression. Cell Host Microbe 10:165-74

61. Mellin JR, Cossart P. 2015. Unexpected versatility in bacterial riboswitches. Trends Genet 31:150-6

62. Mellin JR, Koutero M, Dar D, Nahori MA, Sorek R, Cossart P. 2014. Riboswitches. Sequestration of a twocomponent response regulator by a riboswitch-regulated noncoding RNA. Science 345:940-3

63. Mellin JR, Tiensuu T, Becavin C, Gouin E, Johansson J, Cossart P. 2013. A riboswitch-regulated antisense RNA in Listeria monocytogenes. Proc Natl Acad Sci U S A 110:13132-7

64. Morfeldt E, Taylor D, von Gabain A, Arvidson S. 1995. Activation of alpha-toxin translation in Staphylococcus aureus by the trans-encoded antisense RNA, RNAIII. EMBO J 14:4569-77

65. Nechooshtan G, Elgrably-Weiss M, Altuvia S. 2014. Changes in transcriptional pausing modify the folding dynamics of the pH-responsive RNA element. Nucleic Acids Res 42:622-30

66. Novick RP, Geisinger E. 2008. Quorum sensing in staphylococci. Annu Rev Genet 42:541-64

67. Novick RP, Ross HF, Projan SJ, Kornblum J, Kreiswirth B, Moghazeh S. 1993. Synthesis of staphylococcal virulence factors is controlled by a regulatory RNA molecule. EMBO J 12:3967-75

68. Oliva G, Sahr T, Buchrieser C. 2015. Small RNAs, 5' UTR elements and RNA-binding proteins in intracellular bacteria: impact on metabolism and virulence. FEMS Microbiol Rev 39:331-49

69. Ortega AD, Quereda JJ, Pucciarelli MG, Garcia-del Portillo F. 2014. Non-coding RNA regulation in pathogenic bacteria located inside eukaryotic cells. Front Cell Infect Microbiol 4:162

70. Papenfort K, Forstner KU, Cong JP, Sharma CM, Bassler BL. 2015. Differential RNA-seq of Vibrio cholerae identifies the VqmR small RNA as a regulator of biofilm formation. Proc Natl Acad Sci U S A 112:E766-75

71. Pinel-Marie ML, Brielle R, Felden B. 2014. Dual toxic-peptide-coding Staphylococcus aureus RNA under antisense regulation targets host cells and bacterial rivals unequally. Cell Rep 7:424-35

72. Pizarro-Cerda J, Kuhbacher A, Cossart P. 2012. Entry of Listeria monocytogenes in mammalian epithelial cells: an updated view. Cold Spring Harb Perspect Med 2

73. Quereda JJ, Dussurget O, Nahori MA, Ghozlane A, Volant S, et al. 2016. Bacteriocin from epidemic Listeria strains alters the host intestinal microbiota to favor infection. Proc Natl Acad Sci U S A 113:570611

74. Quereda JJ, Garcia-Del Portillo F, Pucciarelli MG. 2016. Listeria monocytogenes remodels the cell surface in the blood-stage. Environ Microbiol Rep

75. Quereda JJ, Ortega AD, Pucciarelli MG, Garcia-Del Portillo F. 2014. The Listeria Small RNA Rli27 Regulates a Cell Wall Protein inside Eukaryotic Cells by Targeting a Long 5'-UTR Variant. PLoS Genet 10:e1004765

76. Quereda JJ, Pizarro-Cerda J, Balestrino D, Bobard A, Danckaert A, et al. 2015. A Dual Microscopy-Based Assay To Assess Listeria monocytogenes Cellular Entry and Vacuolar Escape. Appl Environ Microbiol 82:211-7 
77. Quereda JJ, Pucciarelli MG. 2014. Deletion of the membrane protein Lmo0412 increases the virulence of Listeria monocytogenes. Microbes Infect 16:623-32

78. Ribet D, Cossart P. 2015. How bacterial pathogens colonize their hosts and invade deeper tissues. Microbes Infect 17:173-83

79. Ruiz de los Mozos I, Vergara-Irigaray M, Segura V, Villanueva M, Bitarte N, et al. 2013. Base pairing interaction between 5'- and 3'-UTRs controls icaR mRNA translation in Staphylococcus aureus. PLoS Genet 9:e1004001

80. Rutherford ST, van Kessel JC, Shao Y, Bassler BL. 2011. AphA and LuxR/HapR reciprocally control quorum sensing in vibrios. Genes Dev 25:397-408

81. Saliba AE, Westermann AJ, Gorski SA, Vogel J. 2014. Single-cell RNA-seq: advances and future challenges. Nucleic Acids Res 42:8845-60

82. Sayed N, Jousselin A, Felden B. 2012. A cis-antisense RNA acts in trans in Staphylococcus aureus to control translation of a human cytolytic peptide. Nat Struct Mol Biol 19:105-12

83. Sayed N, Nonin-Lecomte S, Rety S, Felden B. 2012. Functional and structural insights of a Staphylococcus aureus apoptotic-like membrane peptide from a toxin-antitoxin module. J Biol Chem 287:43454-63

84. Sedlyarova N, Shamovsky I, Bharati BK, Epshtein V, Chen J, et al. 2016. sRNA-Mediated Control of Transcription Termination in E. coli. Cell 167:111-21 e13

85. Sesto N, Touchon M, Andrade JM, Kondo J, Rocha EP, et al. 2014. A PNPase dependent CRISPR System in Listeria. PLoS Genet 10:e1004065

86. Sesto N, Wurtzel O, Archambaud C, Sorek R, Cossart P. 2013. The excludon: a new concept in bacterial antisense RNA-mediated gene regulation. Nat Rev Microbiol 11:75-82

87. Shao Y, Bassler BL. 2012. Quorum-sensing non-coding small RNAs use unique pairing regions to differentially control mRNA targets. Mol Microbiol 83:599-611

88. Shao Y, Bassler BL. 2014. Quorum regulatory small RNAs repress type VI secretion in Vibrio cholerae. Mol Microbiol 92:921-30

89. Sharma CM, Hoffmann S, Darfeuille F, Reignier J, Findeiss S, et al. 2010. The primary transcriptome of the major human pathogen Helicobacter pylori. Nature 464:250-5

90. Silva AJ, Benitez JA. 2016. Vibrio cholerae Biofilms and Cholera Pathogenesis. PLoS Negl Trop Dis 10:e0004330

91. Skorupski K, Taylor RK. 1999. A new level in the Vibrio cholerae ToxR virulence cascade: AphA is required for transcriptional activation of the tcpPH operon. Mol Microbiol 31:763-71

92. Smirnov A, Forstner KU, Holmqvist E, Otto A, Gunster R, et al. 2016. Grad-seq guides the discovery of ProQ as a major small RNA-binding protein. Proc Natl Acad Sci U S A 113:11591-6

93. Sonnleitner E, Gonzalez N, Sorger-Domenigg T, Heeb S, Richter AS, et al. 2011. The small RNA PhrS stimulates synthesis of the Pseudomonas aeruginosa quinolone signal. Mol Microbiol 80:868-85

94. Srivastava D, Harris RC, Waters CM. 2011. Integration of cyclic di-GMP and quorum sensing in the control of vpsT and aphA in Vibrio cholerae. J Bacteriol 193:6331-41

95. Storz G, Vogel J, Wassarman KM. 2011. Regulation by small RNAs in bacteria: expanding frontiers. Mol Cell 43:880-91

96. Svensson SL, Sharma CM. 2016. Small RNAs in Bacterial Virulence and Communication. Microbiol Spectr 4

97. Thiennimitr P, Winter SE, Winter MG, Xavier MN, Tolstikov V, et al. 2011. Intestinal inflammation allows Salmonella to use ethanolamine to compete with the microbiota. Proc Natl Acad Sci U S A 108:17480-5

98. Toledo-Arana A, Dussurget O, Nikitas G, Sesto N, Guet-Revillet H, et al. 2009. The Listeria transcriptional landscape from saprophytism to virulence. Nature 459:950-6

99. Traber KE, Lee E, Benson S, Corrigan R, Cantera M, et al. 2008. agr function in clinical Staphylococcus aureus isolates. Microbiology 154:2265-74 
100. Wagner EG, Romby P. 2015. Small RNAs in bacteria and archaea: who they are, what they do, and how they do it. Adv Genet 90:133-208

101. Wassarman KM. 2007. 6S RNA: a regulator of transcription. Mol Microbiol 65:1425-31

102. Waters CM, Lu W, Rabinowitz JD, Bassler BL. 2008. Quorum sensing controls biofilm formation in Vibrio cholerae through modulation of cyclic di-GMP levels and repression of vpsT. J Bacteriol 190:2527-36

103. Waters LS, Storz G. 2009. Regulatory RNAs in bacteria. Cell 136:615-28

104. Weber GG, Kortmann J, Narberhaus F, Klose KE. 2014. RNA thermometer controls temperaturedependent virulence factor expression in Vibrio cholerae. Proc Natl Acad Sci U S A 111:14241-6

105. Westermann AJ, Forstner KU, Amman F, Barquist L, Chao Y, et al. 2016. Dual RNA-seq unveils noncoding RNA functions in host-pathogen interactions. Nature 529:496-501

106. Westermann AJ, Gorski SA, Vogel J. 2012. Dual RNA-seq of pathogen and host. Nat Rev Microbiol 10:618-30

107. Wright AV, Nunez JK, Doudna JA. 2016. Biology and Applications of CRISPR Systems: Harnessing Nature's Toolbox for Genome Engineering. Cell 164:29-44

108. Wurtzel O, Yoder-Himes DR, Han K, Dandekar AA, Edelheit S, et al. 2012. The single-nucleotide resolution transcriptome of Pseudomonas aeruginosa grown in body temperature. PLoS Pathog 8:e1002945

109. Yu J, Schneiders T. 2012. Tigecycline challenge triggers sRNA production in Salmonella enterica serovar Typhimurium. BMC Microbiol 12:195

110. Zheng J, Shin OS, Cameron DE, Mekalanos JJ. 2010. Quorum sensing and a global regulator TsrA control expression of type VI secretion and virulence in Vibrio cholerae. Proc Natl Acad Sci U S A 107:21128-33

111. Zhu J, Miller MB, Vance RE, Dziejman M, Bassler BL, Mekalanos JJ. 2002. Quorum-sensing regulators control virulence gene expression in Vibrio cholerae. Proc Natl Acad Sci U S A 99:3129-34 


\section{FIGURE LEGENDS}

Figure 1. L. monocytogenes ncRNA examples. (A) A thermosensor regulates the expression of the master regulator of virulence PrfA (inspired by (41)). At $30^{\circ} \mathrm{C}$ the $5^{\prime} \mathrm{UTR}$ of $\mathrm{prfA}$ forms a closed stem

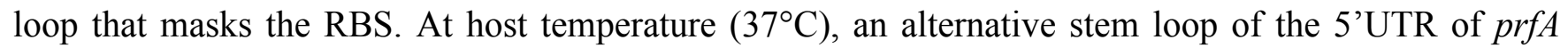
allows ribosome binding and translation. (B) The flagellum biosynthesis excludon (inspired by (86)). The long asRNA anti0677 encodes the motility gene repressor (MogR) and concurrently downregulates the expression of flagellum export apparatus genes (lmo0675-lmo0676-lmo0677) when expressed from the P1 promoter. (C) A riboswitch that binds Vitamin B12 controls expression of the small ncRNA Rli55 which in turn controls expression of eut genes (inspired by (62)). In presence of ethanolamine and absence of Vitamin B12, the antiterminator EutV is phosphorylated and sequestered by the full-length Rli55, what finally avoids eut genes transcription due to termination at the ANTAR elements. In presence of ethanolamine and Vitamin B12, no Rli55 is produced, what liberates the phosphorylated antiterminator EutV. In this situation, EutV dimerize and bind ANTAR element mediating antitermination of the eut transcripts. (D) PocR expression is controlled by vitamin B12 via asPocR (inspired from (63)). In presence of propanediol and absence of Vitamin B12 (Left), AspocR is transcribed as a long antisense RNA and inhibits pocR expression. In the presence of Vitamin B12 and propanediol, the riboswitch induces transcriptional termination and transcription of pocR is allowed. (E) A cell wall protein (Lmo0514) necessary for plasma survival and virulence is regulated by a small ncRNA (inspired from (75)). Rli27 is a small ncRNA highly induced in the intracellular environment and in blood. In BHI broth, Imo0514 is expressed from the constitutive P2 promoter which produces a transcript not accessible to ribosomes. However in the intracellular environment an alternative mRNA is generated from the promoter P1 producing a longer mRNA with an occluded RBS. Rli27 base pair with the $1 m o 0514$ long 5'UTR and activates its translation. 
Figure 2. S. Typhimurium ncRNA examples. (A) Regulation of SPI-1 virulence factor production in the intestine. The S. typhimurium IsrM small ncRNA is highly induced in the intestine. IsrM targets the hilE mRNA and avoids its translation, what finally favors SPI-1 effectors transcription. (B) Regulation of the $m g t C B R$ virulence operon by its ATP-sensing leader region (inspired by (49)). The $m g t C B R$ leader RNA contains the adenine nucleotides-rich $m g t M$ which senses ATP levels. Intracellular ATP concentrations affect the coupling/uncoupling of transcription of the $m g t C B R$ leader and translation of $m g t M$, which determines the formation of alternative stem-loops which finally control transcription elongation into the $\operatorname{mgtCBR}$ genes.

Figure 3. The $V$. cholerae Qrr 1-5 small ncRNAs regulate quorum sensing and virulence (inspired by $(80 ; 88))$. (A) At low cell density, the two-component histidine kinase LuxPQ phosporilate LuxO, via LuxU, and activate qrr gene expression. The Qrr 1-5 small ncRNAs activate the translation of aphA mRNA and repress the translation of hapR mRNA through an antisense mechanism what finally leads to CTX and TCP production and colonization of the host. (B) At high cell density, autoinducers (yellow) bind to LuxPQ which dephosphorylates LuxO, leading to cessation of qrr gene expression and activation of hapR translation. In consequence, proteases and T6SS are expressed what favors escape from the host.

Figure 4. The $S$. aureus RNAIII regulates the transition of the $S$. aureus population from a defensive mode (colonization) to an offensive mode (spreading). (A) At low cell density, AgrC is not phosphorylated which prevents RNAIII production. As a consequence, spa, coa, sbi and rot mRNAs (coding for Protein A, Coagulase, Sbi and the Represor of toxins, respectively) are translated favouring adhesion and colonization. (B) At high cell density, S. aureus produce an autoinducing peptide that is sensed by the histidine kinase AgrC causing its autophosphorylation. Then, this phosphoryl group is 
transferred to the response regulator AgrA which in turn activates transcription of the regulatory RNAIII. This small RNA posttranscriptionally regulates several target mRNAs. On one hand, pairing of RNAIII to spa, coa, sbi and rot prevents binding of ribosomes. On the other hand, RNAIII interaction with hla (coding for $\alpha$-hemolysin) prevents the formation of an inhibitory structure sequestering the SD which finally facilitates translation. Thus, RNAIII finally induces the production of toxins favouring a spreading mode. 
(A) The PrfA thermosensor

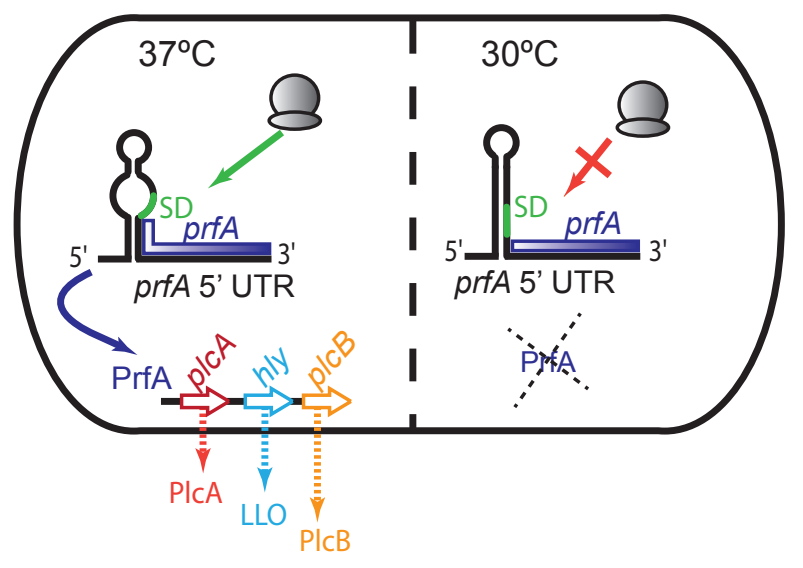

(C) Rli55 sequesters EutV
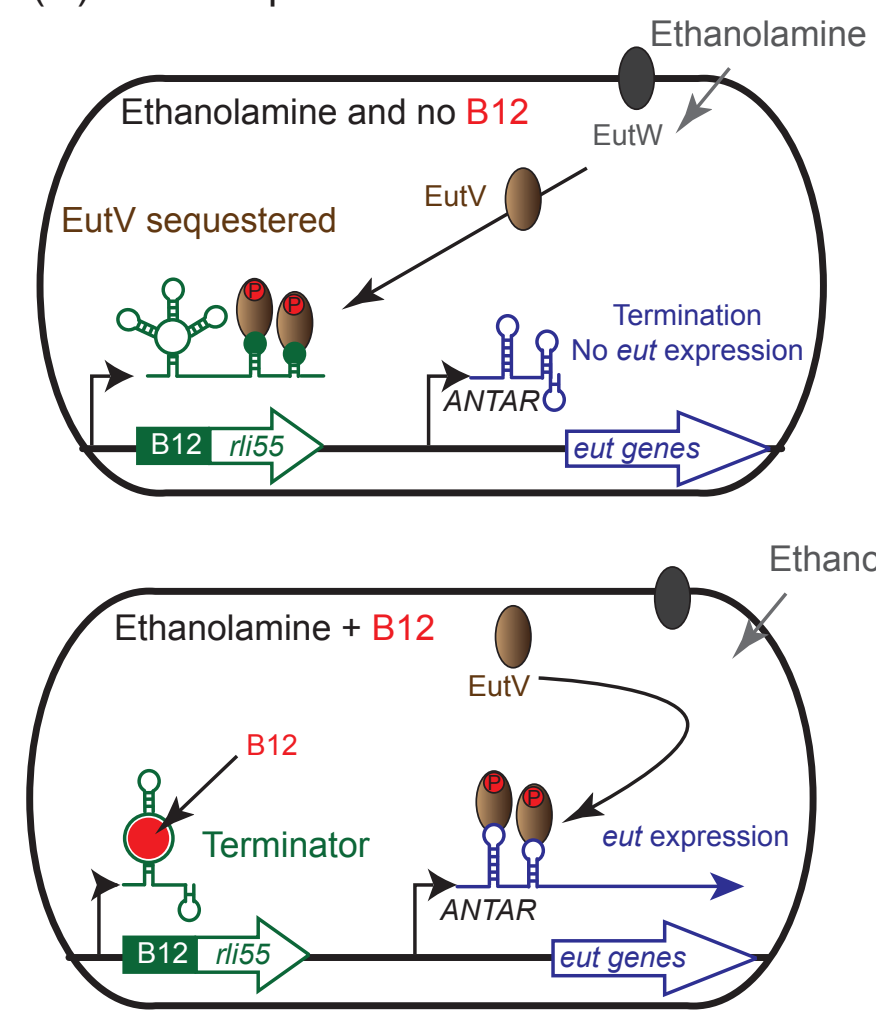

(B) The motility excludon

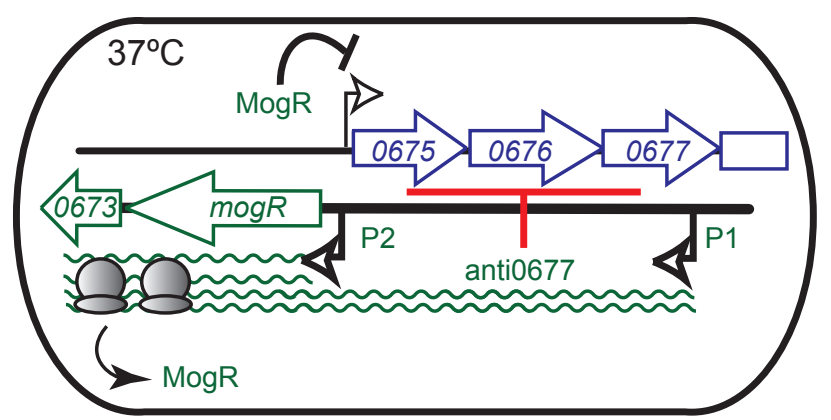

(D) pocR is controlled by B12 via asPocR

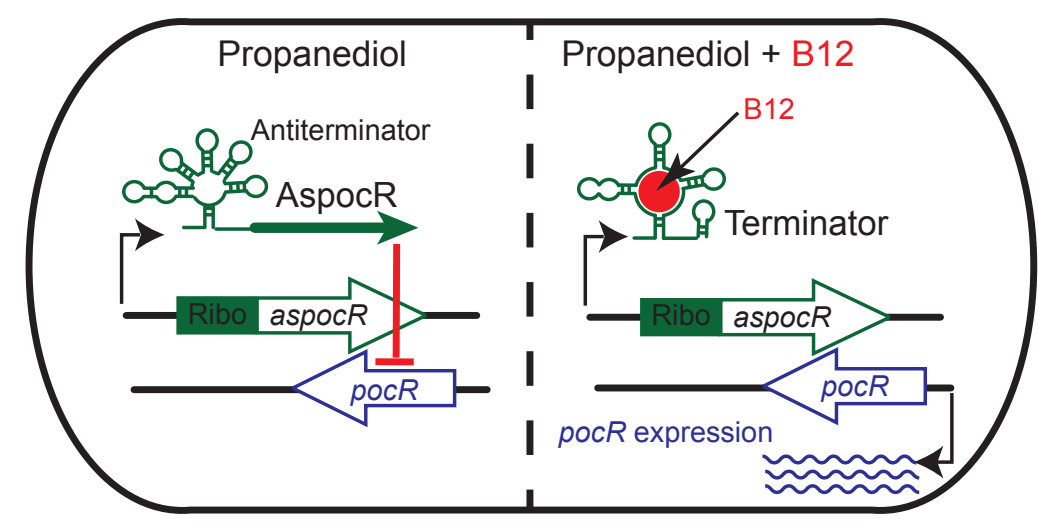

(E) Translation activation of Lmo0514 by Rli27

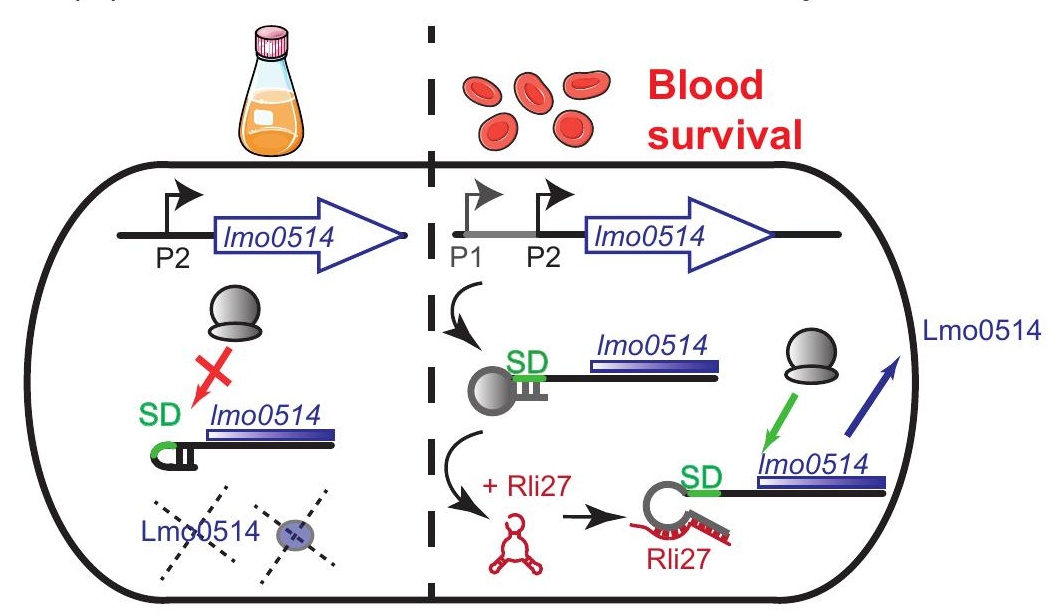

Figure 1 
Salmonella Typhimurium

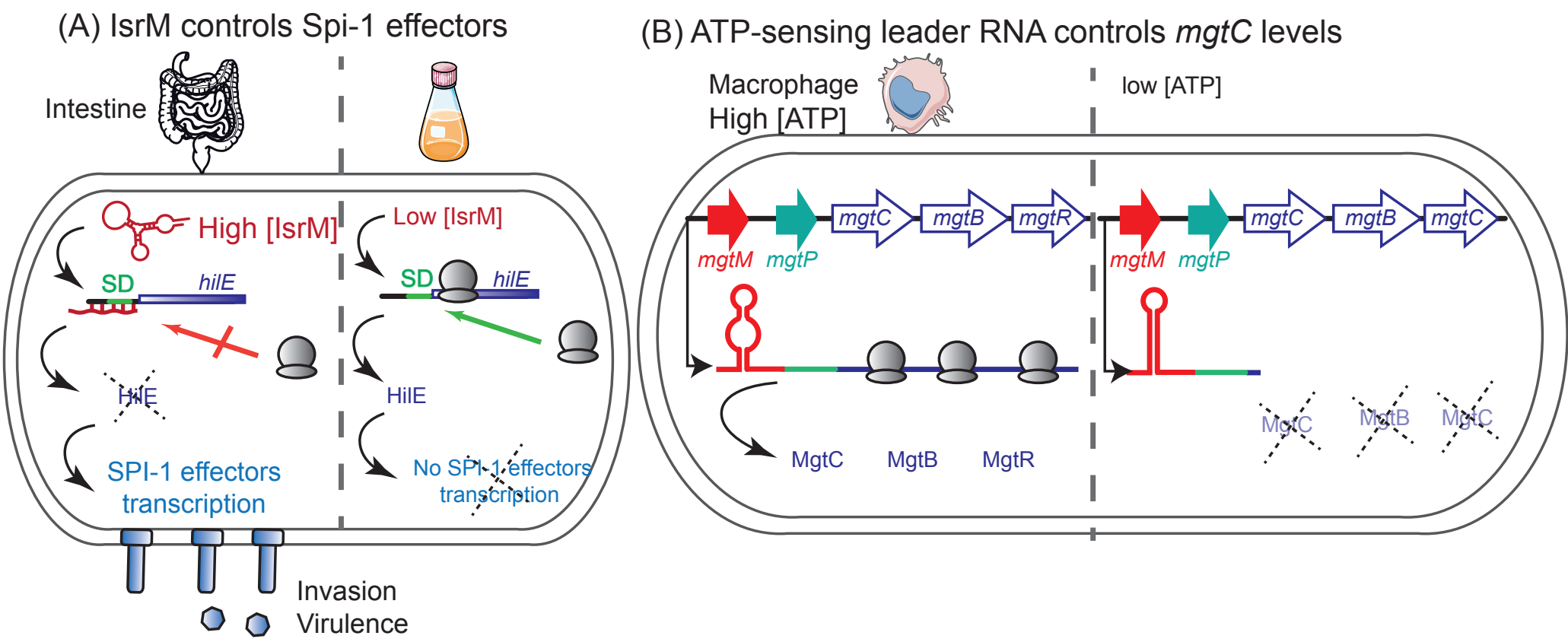

Figure 2 


\section{Vibrio Cholerae}

(A) Low cell density

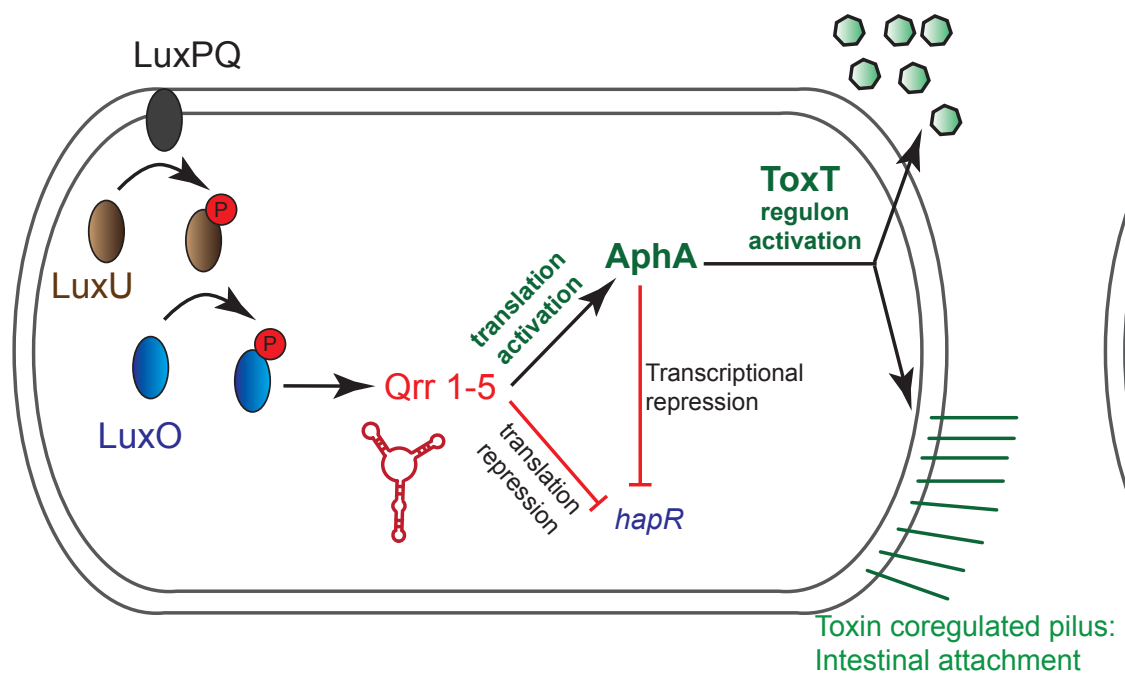

Figure 3
(B) High cell density

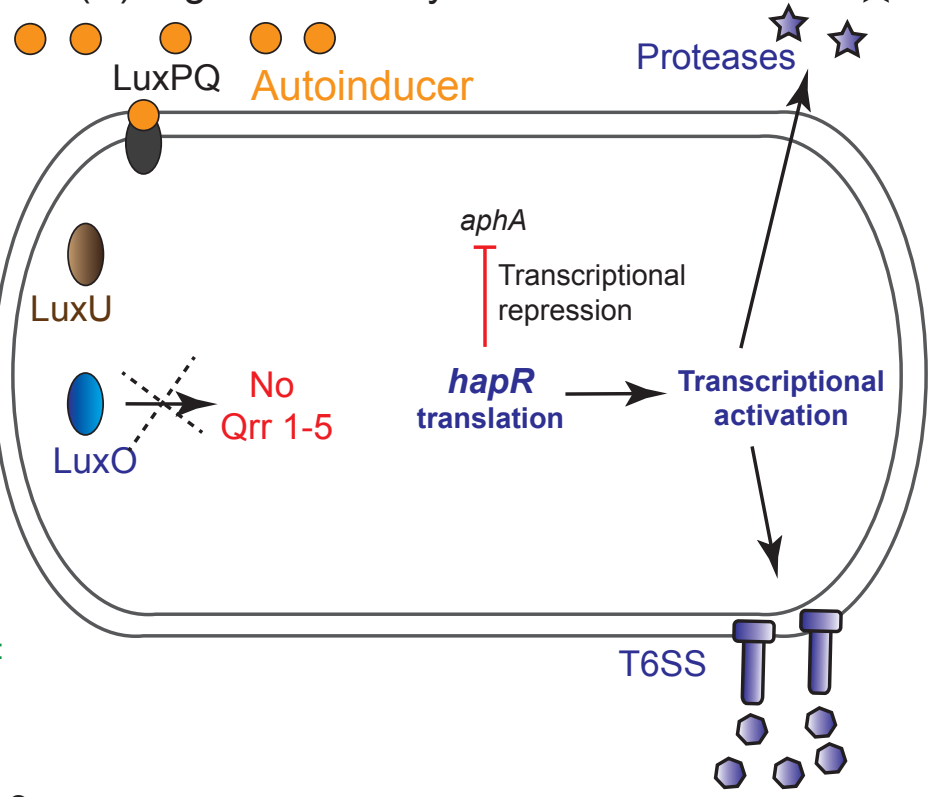



(A) Low cell density: colonization
(B) High cell density: spreading

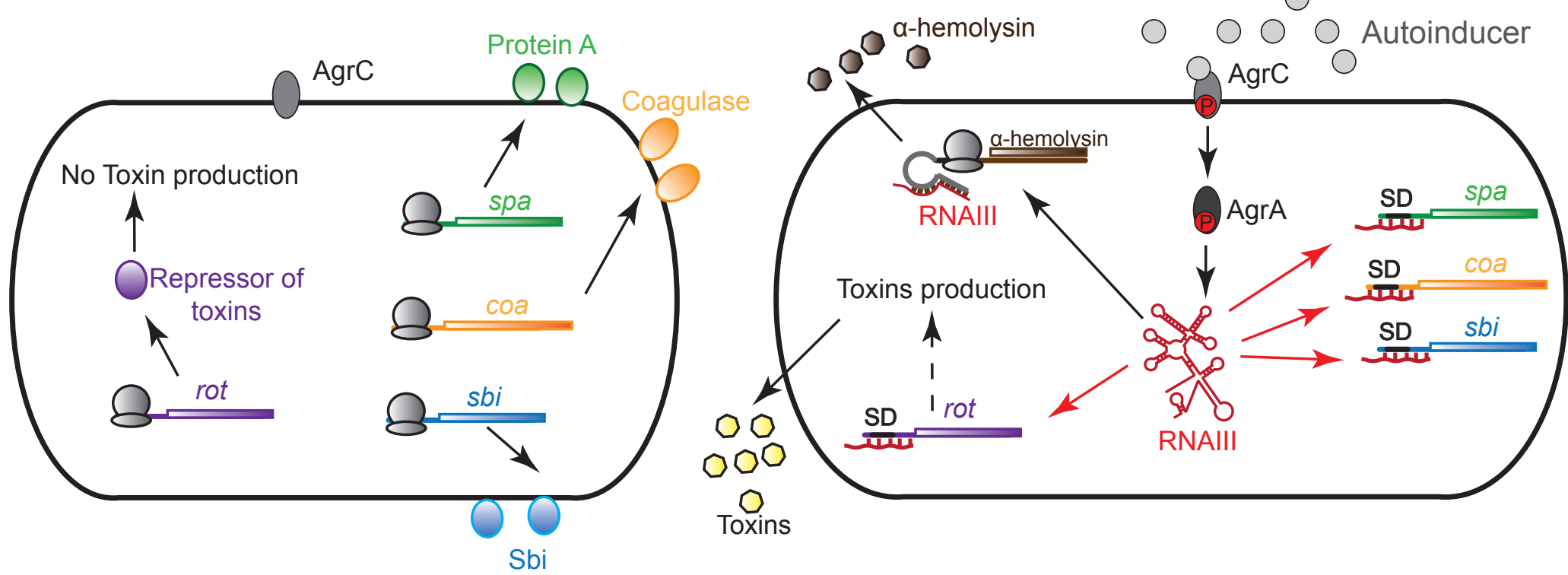

Figure 4 